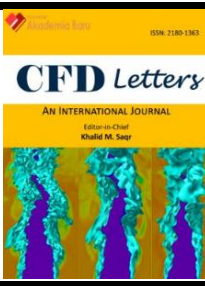

\title{
Performance Analysis of Highway Wind Turbine Enhanced with Wind Guide Vanes Using the Taguchi Method
}

\author{
Mohamad Zahid Mazlan ${ }^{1}$, Fazila Mohd Zawawi ${ }^{1,},{ }^{*}$, Teeab Tahzib ${ }^{1}$, Kamarulafizam Ismail $^{1}$, Syahrullail \\ Samion $^{1}$ \\ 1 School of Mechanical Engineering, Faculty of Engineering, Universiti Teknologi Malaysia, 81310 Skudai Johor, Malaysia
}

\section{ARTICLE INFO}

\section{Article history:}

Received 14 October 2020

Received in revised form 18 November 2020

Accepted 19 November 2020

Available online 16 March 2021

\section{Keywords:}

VAWT; Savonius; Moving car; Highway; CFD; Dynamic Mesh; Transient; 1DOF; Taguchi Method

\section{ABSTRACT}

Considerable efforts have been made by researchers to study the interaction between moving vehicles and wind turbines. The Savonius vertical-axis wind turbine was chosen due to its effectiveness in low-wind speed conditions. Speeding vehicles produce a scattered and non-uniform wind flow with disturbances. Hence, to prevent a negative torque, a row of wind guide vane panels was arranged in front of the blades of a wind turbine. The wind guide vane had the shape of an NACA4412 aerofoil to reduce the loss of wind energy, and to further increase wind velocity. A number of CFD simulations were designed using the Taguchi method to determine the optimum conditions for the power coefficient of the wind turbine in terms of the effects of three factors, namely, the distance between the guide vanes $(d)$, the angle of the guide vanes $(\alpha)$, and the speed of the moving $\operatorname{car}\left(V_{c}\right)$. An orthogonal array of $L_{9}\left(3^{3}\right)$ was designed. In addition, to observe the effects of the wind velocity induced by the moving vehicle, the wind turbine was incorporated with one degree of freedom (1DOF). The results showed that the speed of the moving car played a major role in determining the power coefficient. The order of influence of each factor was ranked as $V_{c}>\alpha>d$. The performance of the wind turbine was sensitive to the speed of the car and the angle of the guide vanes, whereas it was insensitive to the distance between the guide vanes. Furthermore, the analysis of the signal-to-noise $(\mathrm{S} / \mathrm{N})$ ratio suggested that the optimal combination of factors for a maximum power coefficient were $d=0.4 \mathrm{~m}, \alpha=30^{\circ}$, and $V_{C}=30 \mathrm{~m} / \mathrm{s}$. The optimum setting increased the $\mathrm{Cp}$ to $26 \%$ compared to the $\mathrm{Cp}$ that was produced without the installation of the guide vanes.

\section{Introduction}

Currently, the Malaysian Government is seeking to develop the most potential forms of renewable energy in the coming years, namely, solar and biomass energy. The percentage of electricity that is generated by wind and tidal-based renewable energy resources is too small and negligible due to the potential problems of these resources. For instance, wind turbine farms are not applicable in Malaysia because the average annual wind speed ranges between 2 and $3 \mathrm{~m} / \mathrm{s}$ [1]. On the other hand, the average velocity of the aerodynamic wake of cruising vehicles is approximately $34 \mathrm{~m} / \mathrm{s}$ near the car body and, depending on the position of the wind turbine, it can strike the wind

\footnotetext{
* Corresponding author.

E-mail address: fazila@mail.fkm.utm.my (Fazila Mohd Zawawi)
} 
turbine blades at speeds of up to $6 \mathrm{~m} / \mathrm{s}[2,3]$. Therefore, with a highway network totalling 49,935 km in length, the turbulent wind induced by speeding passenger vehicles on highways does not appear to be negligible, and is a highly potential wind energy resource that is sustainable and renewable.

Generally, wind speeds that are induced by moving vehicles can reach up to 5 to $6 \mathrm{~m} / \mathrm{s}$ [4]. As such, a suitable wind turbine needs to be designed and developed that can operate under low wind conditions. Other challenges include the non-uniform and unpredictable wind flow on highways. Speeding vehicles produce a scattered wind flow with disturbances from crosswinds and other external wind sources. A study by Santhakumar et al., [5] revealed that vehicles moving in opposite directions affect the rotational speed of wind turbines and cause a negative drag force on the blades. Therefore, as an alternative, a curtain system can be placed in front of the wind turbine blades to prevent a negative torque [6]. There are many types of curtain systems such as 'wind boosters', 'wind tunnels', 'deflecting panels', 'wind curtains' and 'guide vane nozzles' [7-10]. All of these have been designed to increase the performance of wind turbines. There have been improvements and drawbacks, but from the literature many of the designs can, nevertheless, increase the performance of wind turbines.

The proposed curtain system for this project was made up of wind panels or what is referred to as 'guide vanes' to concentrate a turbulent wind flow onto the wind turbine blades and increase the wind speed with suitable operating factors. The main concern was the loss of wind energy from the leading edge to the trailing edge when the wind travelled past the rectangular-shaped panels. The shape of the guide vanes plays an important role in reducing the air drag from the incoming wind flow. Hence, to reduce wind energy losses and to further increase the wind velocity, the rectangularshaped panels were replaced by NACA 4412 aerofoil-shaped panels. In airfoil perspective, relative wind on top of an airfoil experiences a constrict airflow lines resulted by low pressure area. According to Bernoulli equation when pressure is reduces, speed of fluid also increases across airfoil. The guide vane angle and the distance between the guide vanes were analysed to determine the effectiveness of having the proposed curtain system. Figure 1 shows the concept of having the guide vanes to direct the wake of the vehicles to the wind turbine rotor when fast-moving vehicles pass by.

Many existing literatures in Computational Fluid Dynamics (CFD), regarding moving vehicle cases were done in static state where the vehicle is still in one place and wind speed is inserted at inlet as an input variable to observe the flow pattern such as study done by Hegde et al., [3]. However, these simplification does not represent real-life situation where vehicle should be moving instead of being stationary. In addition, many studies towards understanding behaviour of wind turbine performance at highway setting whether experimental or numerical were using uniform wind velocities instead unsteady non-uniform wind velocities such as research done by Tian et al., [19]. This practice does not combine moving vehicle and wind turbine in one computational domain.

The potential of this study is finally Malaysia can achieve the objective of reducing the reliance on fossil fuel by providing sufficient data for feasible alternative of supplying reliable electrical energy to the lighting system on highway network. This study aims to solve the problems stated above by using three-dimensional computational fluid dynamics simulations. The HmSWT have specific design to increase the efficiency on harvesting aerodynamic wake from moving vehicle. Furthermore, to reduce negative torque a novel design of curtain system by installing the optimum arrangement of guide vane with airfoil NACA 4412 shape to further increase the HmSWT performance.

In summary, this study was aimed at recovering the wake of moving vehicles on the highway using a wind turbine that can operate under a low wind speed and turbulent wind flow. In addition, to improve the performance of the wind turbine, a curtain system, consisting of NACA4412 aerofoilshaped guide vanes, was placed near the wind turbine blades. A parametric study of the arrangement of the guide vanes was conducted to obtain the optimum configuration for the guide vanes using the 
Taguchi method of design of experiment. The geometric models were designed using SolidWorks CAD software, while the numerical domain modelling and analysis were done using the ANSYS CFD software. This research used the approach of a dynamic simulation instead of a stationary vehicle simulation to resemble a real moving vehicle on the road, where the wind turbine would only rotate after the wind flow induced by the moving vehicle reached the rotor.

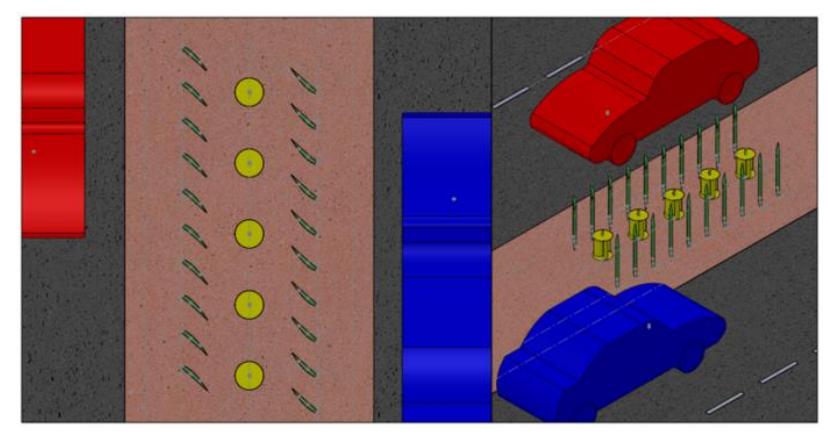

Fig. 1. Proposed Curtain System

\section{Methodology}

\subsection{Geometric Modelling}

The 3D models were designed using SolidWorks software. The models needed for this research were the car model, wind turbine model, and the model of the NACA 4412 aerofoil-shaped guide vanes. These models were built separately, before being combined for a computational fluid dynamic analysis.

\subsubsection{Modelling of car}

Figure 2 shows a simplified model of the Proton Saga. The dimensions of the car model were identical to those of a real Proton Saga. The wheels were not included in the simplified model as the flow field was small, and thus, the influence of the wheels could be ignored in the simulation [11]. The overall dimensions of the car were $4.3 \mathrm{~m} \times 1.7 \mathrm{~m} \times 1.5 \mathrm{~m}$ (length $\times$ width $\times$ height).

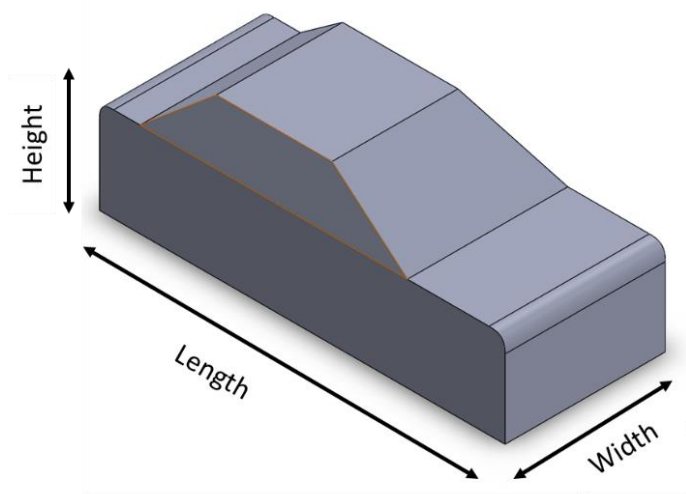

Fig. 2. Model of Proton Saga Car

\subsubsection{Modelling of wind turbine}

The design of the Savonius wind turbine was a factor that had a significant effect on the performance of the wind turbine. The desired overlapping ratio (e/2) was set to 0.15 for the best air 
circulation inside the wind rotor [12]. Besides that, three rotor blades gave a better and more stable performance than two or four rotor blades [13]. Next, the plates covering both ends of the wind turbine had a diameter of $400 \mathrm{~mm}$, and these were able to improve the performance of the wind turbine [14]. Figure 3 shows the design while Table 1 shows the dimensions that resulted from the literature review.
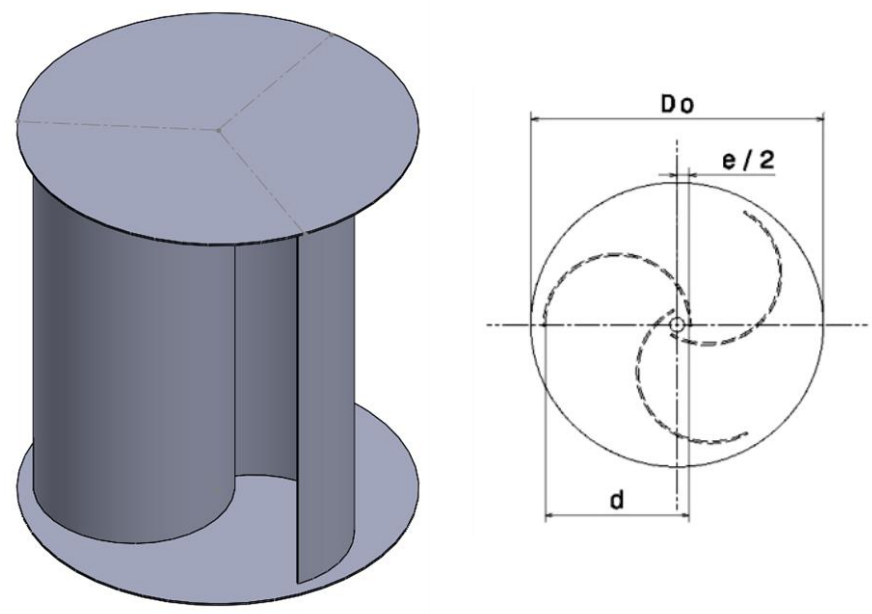

Fig. 3. Savonius Wind Turbine Model

Table 1

Highway micro Savonius Wind Turbine Specification

\begin{tabular}{llllll}
\hline$D_{\circ}$ & D & $d$ & $H$ & e & $d_{\text {shaft }}$ \\
\hline $400 \mathrm{~mm}$ & $364 \mathrm{~mm}$ & $197 \mathrm{~mm}$ & $437 \mathrm{~mm}$ & $30 \mathrm{~mm}$ & $15 \mathrm{~mm}$ \\
\hline
\end{tabular}

\subsubsection{Modelling of guide vanes}

The guide vane model had the shape of an NACA4412 aerofoil. The model was constructed using the aerofoil points in the DAT file provided in the Aerofoil-Tools website [15]. Then, the DAT file was read into the SolidWorks software to form a solid body. The aerofoil was 1 metre in length, while the width was 0.5 metres, as shown in Figure 4 . Both the length and width were fixed parameters, but the arrangement of the guide vanes was varied.

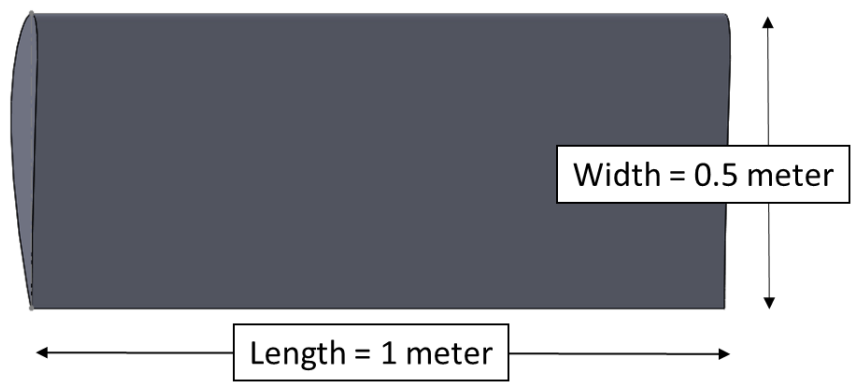

Fig. 4. Guide Vane Model

\subsection{Taguchi Method}

The objective of this study was to apply the Taguchi method for a numerical investigation to improve the performance of a highway micro Savonius wind turbine integrated with a proposed 
curtain system under the influence of a wake flow by a moving car. Three factors, namely, the distance between the guide vanes $(d)$, the angle of the guide vanes $(\alpha)$, and the speed of the $\operatorname{car}\left(V_{c}\right)$, were selected for the analysis and optimization. The factors were denoted as Factors $A, B$ and $C$, respectively. The details of the control factors and levels are given in Table 2.

Table 2

Factors and Levels of CFD-Taguchi Method

\begin{tabular}{lllllll}
\hline Factor & Control Parameter & Notation & Unit & Level & \\
& & & & 1 & 2 & 3 \\
\hline A & Distance between guide vanes & $d$ & $\mathrm{~m}$ & 0.4 & 0.5 & 0.6 \\
$\mathrm{~B}$ & Angle of guide vanes & $\alpha$ & $\circ$ & 30 & 40 & 50 \\
$\mathrm{C}$ & Car speed & $V_{c}$ & $\mathrm{~m} / \mathrm{s}$ & 20 & 25 & 30 \\
\hline
\end{tabular}

If the three factors and three levels were all considered for a full-range investigation, a total of $\left(3^{3}\right)=27$ simulation runs would have had to be carried out, and it would have taken time and effort to fully investigate all the cases. Therefore, a suitable orthogonal array, namely an L9 orthogonal array with three parameters and three levels, was selected by an array selector. Only 9 simulation runs were required to accurately analyse the performance of the wind turbine integrated with guide vanes. After selecting the correct orthogonal array, each independent variable was assigned to each column in the pre-determined orthogonal array matrix, as shown in Table 3.

Table 3

L9 Orthogonal Array Matrix

\begin{tabular}{llll}
\hline Cases & Factors & & \\
& A (GV distance) & B (GV angle) & C (Car speed) \\
\hline 1 & A1 $(0.4 \mathrm{~m})$ & B1 $\left(30^{\circ}\right)$ & C1 $(20 \mathrm{~m} / \mathrm{s})$ \\
2 & A1 $(0.4 \mathrm{~m})$ & B2 $\left(40^{\circ}\right)$ & C2 $(25 \mathrm{~m} / \mathrm{s})$ \\
3 & A1 $(0.4 \mathrm{~m})$ & B3 $\left(50^{\circ}\right)$ & C3 $(30 \mathrm{~m} / \mathrm{s})$ \\
4 & A2 $(0.5 \mathrm{~m})$ & B1 $\left(30^{\circ}\right)$ & C2 $(25 \mathrm{~m} / \mathrm{s})$ \\
5 & A2 $(0.5 \mathrm{~m})$ & B2 $\left(40^{\circ}\right)$ & C3 $(30 \mathrm{~m} / \mathrm{s})$ \\
6 & A2 $(0.5 \mathrm{~m})$ & B3 $\left(50^{\circ}\right)$ & C1 $(20 \mathrm{~m} / \mathrm{s})$ \\
7 & A3 $(0.6 \mathrm{~m})$ & B1 $\left(30^{\circ}\right)$ & C3 $(30 \mathrm{~m} / \mathrm{s})$ \\
8 & A3 $(0.6 \mathrm{~m})$ & B2 $\left(40^{\circ}\right)$ & C1 $(20 \mathrm{~m} / \mathrm{s})$ \\
9 & A3 $(0.6 \mathrm{~m})$ & B3 $\left(50^{\circ}\right)$ & C2 $(25 \mathrm{~m} / \mathrm{s})$ \\
\hline
\end{tabular}

\subsection{CFD Simulation}

\subsubsection{Computational domain}

The computational domain for the deforming mesh had to be in a single contiguous mesh system. As this study involved a moving car and a rotating wind turbine, thus, the domain was divided into several blocks to separate the meshing process for different working zones. The first zone was the Translational Zone, where the car model was subtracted out to form a cavity. Next, was the Deforming Zone, which was placed in the front and back of the Translational Zone. The Deforming Zone would compensate for the mesh deformation while the Translational Zone was moving forward. The third zone was the Rotating Zone, which enclosed the wind turbine with a 0.02-m tolerance. The last zone was the Stationary Zone, which was then divided into 5 separate stationary zones according to the block division. Stationary Zone 3, in particular, had an aerofoil cavity that acted as the guide vanes, and a rotating zone inside of it.

As shown in Figure 5 and Table 4, the domain was a rectangular box measuring $165.0 \mathrm{~m}$ in length, $3.5 \mathrm{~m}$ in height, and $12.0 \mathrm{~m}$ in width. The total distance travelled by the moving car was fixed at 150 
$\mathrm{m}$. The car was also placed $35 \mathrm{~m}$ away from the wind turbine. After the moving car had passed by the wind turbine, the car continued to travel a remaining $115 \mathrm{~m}$ to cover the total travel distance of 150 $\mathrm{m}$. The long length of the total computational domain was to ensure that the wake flow produced by the cruising vehicle would stabilise before it reached the wind turbine blades and the moments- offorce on the wind turbine reached a steady state.

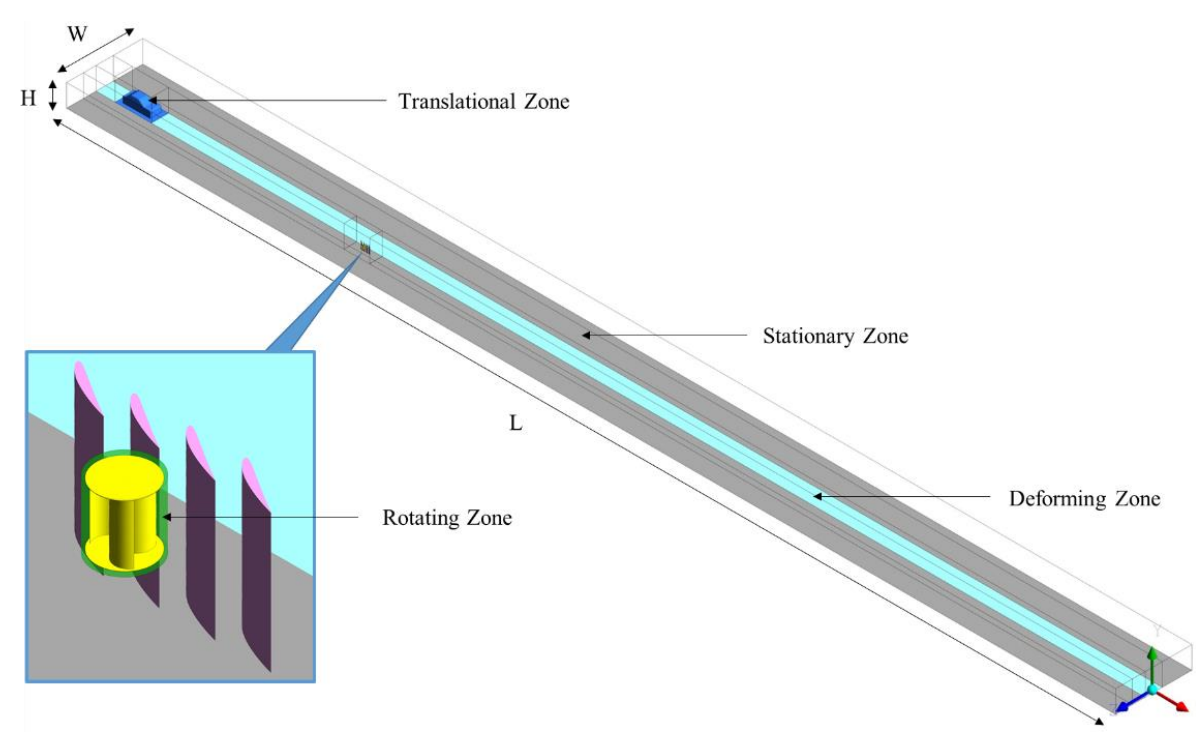

Fig. 5. Total Computational Domain Zones

Table 4

Total Computational Domain Dimensions

\begin{tabular}{lll}
\hline $\mathrm{L}$ & $\mathrm{H}$ & $\mathrm{W}$ \\
\hline $165.0 \mathrm{~m}$ & $3.5 \mathrm{~m}$ & $12.0 \mathrm{~m}$ \\
\hline
\end{tabular}

The wind turbine was designed to convert the wake flow from incoming vehicles moving from two opposite directions. Thus, it had to be installed on a highway median in order to work at its maximum performance. However, to facilitate the simulation setup and reduce the computational time, a few simplifications had to be considered. One such simplification was that only one side of the highway was taken into consideration.

This numerical investigation was focused on only one wind turbine. The micro-sized wind turbine was unsuitable for placement close to the ground, and needed to be supported by a pole or external frame [16]. However, for simplification purposes, only the rotating part of the wind turbine was positioned in the domain fixed at $0.5 \mathrm{~m}$ above ground level. The proposed curtain system also had a few constant variables such as the size of the NACA 4412 aerofoil, with a length of $1 \mathrm{~m}$ and width of $0.5 \mathrm{~m}$, which remained the same for all the studied cases. In addition, the number of guide vanes in the computational domain was kept constant at 4 guide vanes in a single row.

\subsubsection{Meshing process}

A computational grid mesh was generated using the Ansys Meshing application. For this project, the mesh grid consisted of a hybrid of structured and unstructured meshes made by slicing the domain into different blocks. Only critical areas with complex shapes used the unstructured mesh approach. Figure 6 shows the mesh setup for the respective zones. The Translational Zone, Rotating Zone and Stationary Zone 3 had unstructured grids for housing the complex geometries. The other zones, which were regular, had structured grids. Figure 7 shows in detail the mesh types in 3D. 


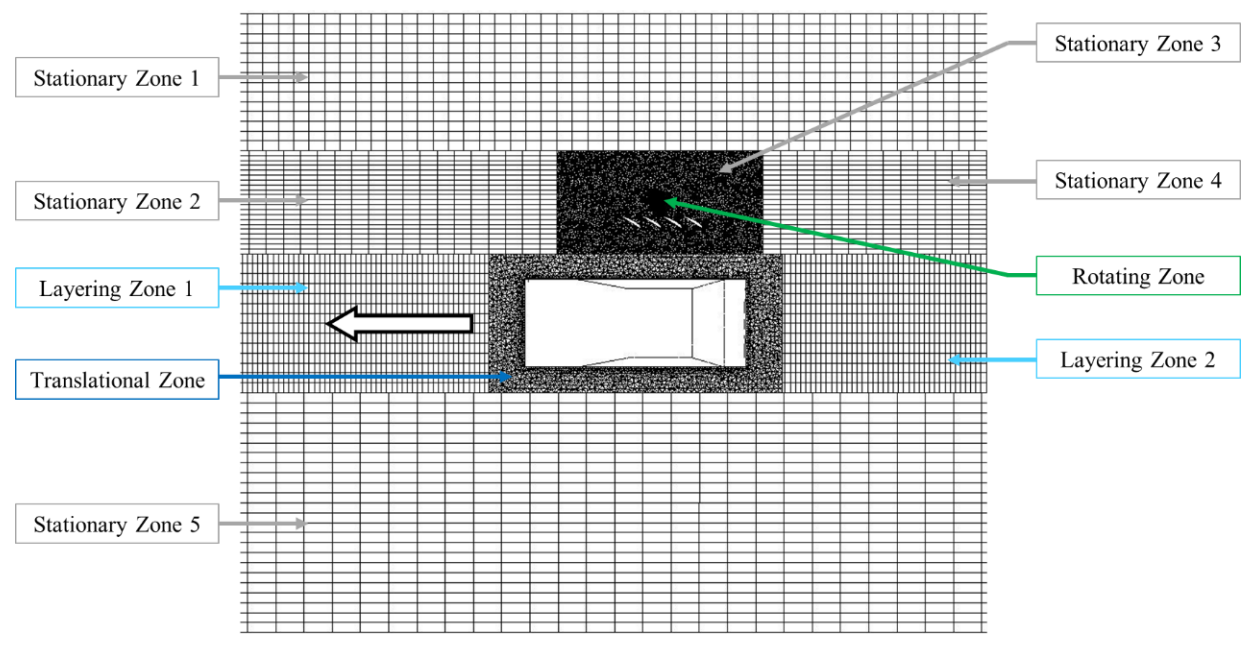

Fig. 6. Hybrid Mesh

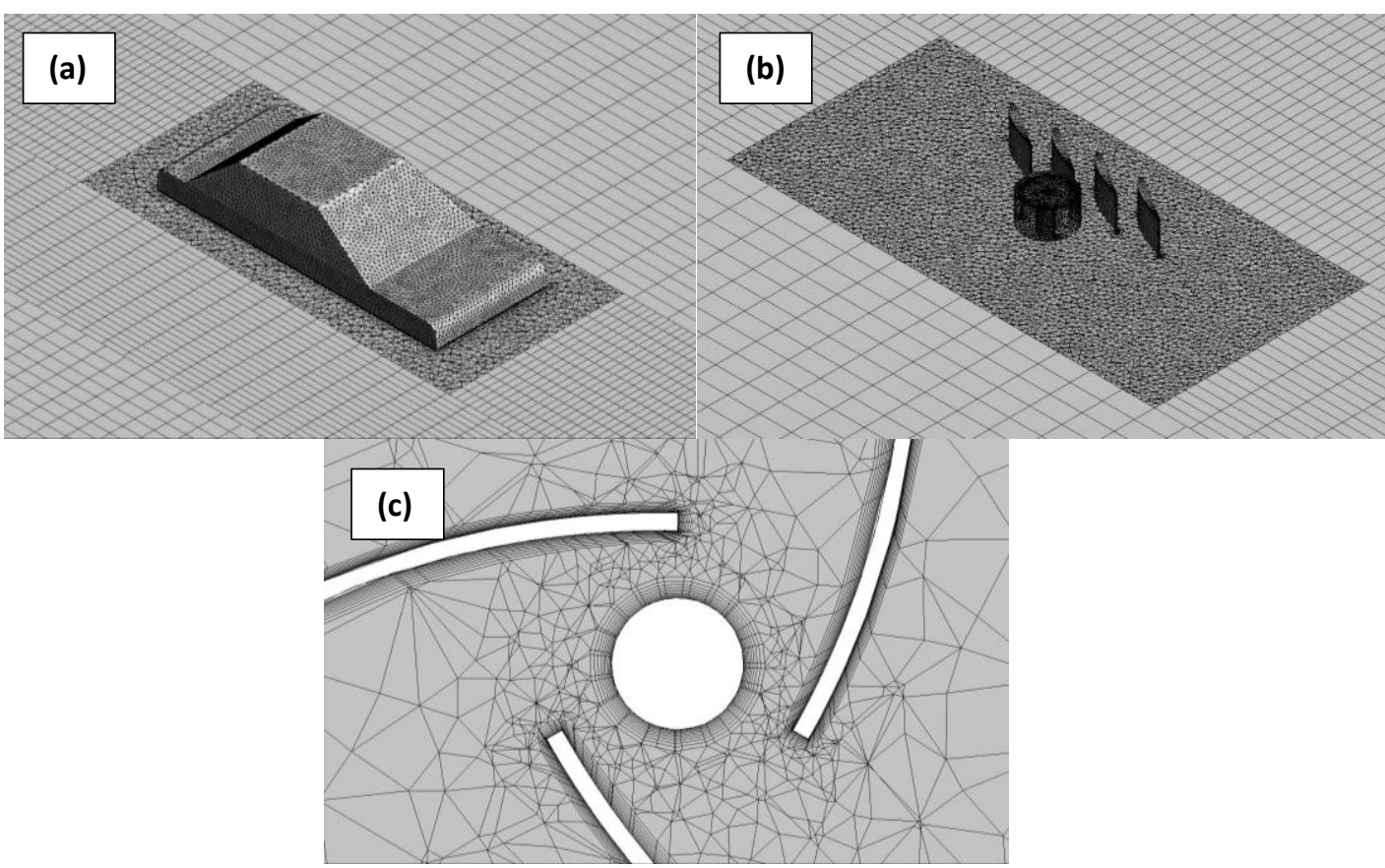

Fig. 7. Detailed mesh view of (a) Translational Zone, and (b) Stationary Zone 3 and Rotating Zone (c) Refinement Cell near Wind Turbine Walls

In this study, a dynamic layering technique was used to obtain the boundaries of the moving car in the computational domain. The dynamic layering technique refers to the addition or removal of layers of cells adjacent to a moving boundary based on the height of the layer adjacent to the moving surface. Before importing the mesh file to the Ansys Fluent to control the volume of fluid for the analysis, the ideal layer height was set at a constant of $\mathrm{h}=0.1 \mathrm{~m}$ across Layering Zone 1 and Layering Zone 2.

\subsubsection{Transient simulation}

The turbulence model used in the numerical simulation was the k- $\omega$ SST, referred to previously, which was successful in capturing the turbulence flow well compared to other turbulence models $[17,18]$. The best representation of the interaction between the moving vehicle and the wind turbine was obtained by implementing a 1-DOF method in the Ansys Fluent Six DOF Properties. Only one 
degree of freedom at the vertical rotational axis of the wind turbine was activated, while other yawing and pitching motions were unnecessary. The moment of inertia needed for the 1-DOF rotation at the $\mathrm{Y}$-axis based on the rotational axis of the wind turbine was calculated using Eq. (1) below. By specifying the ABS material to the geometry of the wind turbine, the resulting mass was $1.43 \mathrm{~kg}$, while the radius of the wind turbine was $0.182 \mathrm{~m}$. Hence, from Eq. (1), the moment of inertia was approximately $0.05 \mathrm{~kg} \cdot \mathrm{m}^{2}$.

$I=m r^{2}$

From the Solution Methods of the Ansys Fluent, this study used the 'Coupled Scheme' for the pressure-velocity coupling in all the studied cases because the numerical investigation of the relationship between moving vehicles and wind turbines by Tian et al., [19] stated that a fast convergence for simulations can be obtained with a coupled algorithm. For the spatial discretization, a 'least squares cell base' was used for the gradient, and a 'second-order upwind' was used for the pressure, momentum, turbulent kinetic energy, and specific dissipation rate. According to the Ansys User's Guide, second-order algorithms produce accurate results compared to first-order algorithms because the former algorithms reduce error interpolations and false numerical diffusions.

Each simulation case had a different simulation time due to the different speeds of the car, but the travelled distance was the same at $150 \mathrm{~m}$. Therefore, for speeds of $20 \mathrm{~m} / \mathrm{s}, 25 \mathrm{~m} / \mathrm{s}$ and $30 \mathrm{~m} / \mathrm{s}$, the simulation times were 7.5 seconds, 6 seconds and 5 seconds, respectively. Hence, to avoid any error, the time steps were set accordingly, so that the displacement of the moving car at each time step did not exceed the minimum size of the layering zone.

\section{Validation Study}

\subsection{Grid Independent Test (GIT)}

One case of a combined factor was chosen to perform the Grid Independent Test (GIT) from a lower, medium and high number of elements. Approximately, the lower mesh had 3 million cells, the medium mesh had 4 million cells, and the high mesh had 5 million cells. Figure 8 shows the torque coefficient generated by each mesh. The lower mesh predicted a slightly lower and non-uniform trend of $\mathrm{C}_{m}$ compared to the medium and high meshes, which provided the same results. Hence, the medium mesh was chosen for all the cases that followed. Overall, the medium mesh consisted of 1.2 million cells in the Rotating Zone, 0.15 million cells in the Translational Zone, 0.4 million cells in the layering zones, and 2.2 million cells in the static zones.

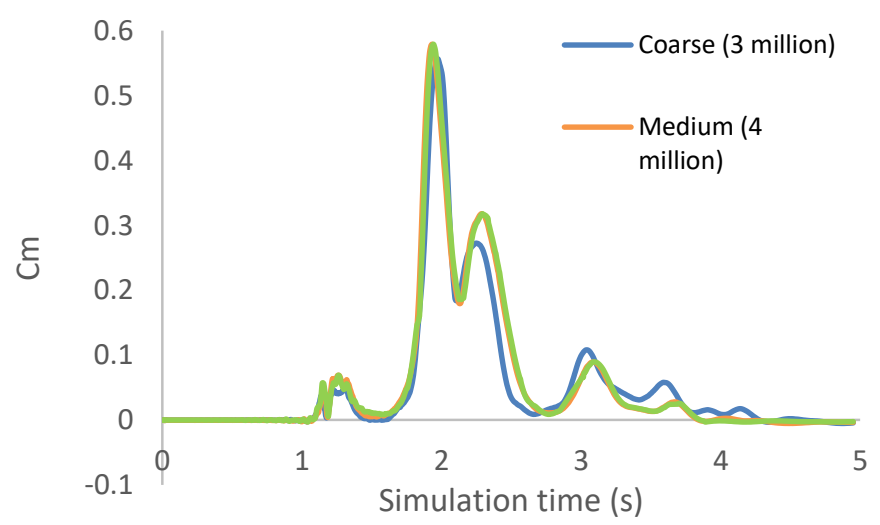

Fig. 8. Moment Coefficient of Wind Turbine for Different Numbers of Cells 


\subsection{Wall Function, $Y_{+}$}

In fluid dynamics, the law of wall states that the average velocity of a turbulent flow is proportional to the logarithm of the distance from that point to the wall. In other words, $\mathrm{Y}+$ is the distance of the first point from the wall, which captures the fluid flow in fluid dynamics. In mathematical terms, the dimensionless $Y+$ is the ratio between the distance, $y$ from the wall and the friction velocity over the kinematic viscosity. The main purpose of the wall function is to validate the capability of the first cells around the car body to capture the viscosity effect, where the $Y+$ value at the surface of the car is monitored. In order to achieve the first cells that are good, the $Y+$ value should be less than 10. A perfect $Y+$ value would be 1 . For this simulation, the wall, $y+$ of a wind turbine was set under 0.5 , and the walls, $y+$ of the guide vanes and car model were set in the range of between 10 and 50 . This showed that the model was very capable of capturing the viscosity effect.

\subsection{Validation Method}

The validation process involved the use of a numerical model, which was separated into three sections according to the geometry involved in this study. The numerical investigation by Selvaraju et al., [20] found that a typical sedan car has a coefficient of drag (Cd) value of 0.35. For this study, a simplified sedan car model based on the Proton Saga 2016 model was used. The car model was tested with an inlet flow velocity of $30 \mathrm{~m} / \mathrm{s}$, same as in the previous CFD study. In addition, the Proton Saga Review by Lye [21] mentioned that the drag coefficient of the new car model was reduced to 0.33. The comparison of the drag coefficient (Cd) of the Proton Saga in previous CFD studies with that of the current car model for this simulation, as shown in Table 5, revealed that a decent prediction of the drag coefficient, with an error of between $5 \%$ and $10 \%$, was obtained.

\section{Table 5}

Comparison of coefficient of drag of car model from various sources

\begin{tabular}{ll}
\hline & Cd \\
\hline CFD & 0.37 \\
CFD by Selvaraju et al., [20] & 0.35 \\
Proton Saga Drag Coefficient by Lye [21] & 0.33 \\
\hline
\end{tabular}

Next, was the validation of the guide vane model, which had the shape of the NACA 4412 aerofoil. The aerodynamic drag was measured with a Reynolds number of $3 \times 10^{6}$ and an angle of attack of $14^{\circ}$. The result obtained was in agreement within 3.18\% of the NACA published data [22]. Lastly, the wind turbine model was validated by a simulation that was conducted using the same wind turbine design with a wind velocity of $20 \mathrm{~m} / \mathrm{s}$. Figure 9 shows a comparison of the performance in terms of the power coefficient between the simulation method and the experimental method by Torresi et al., [23]. The simulation, performed at a tip-speed ratio ranging between 0.2 to 1 , showed that the simulation data were very close to the experimental data for the optimum performance curve of the Savonius wind turbine. 


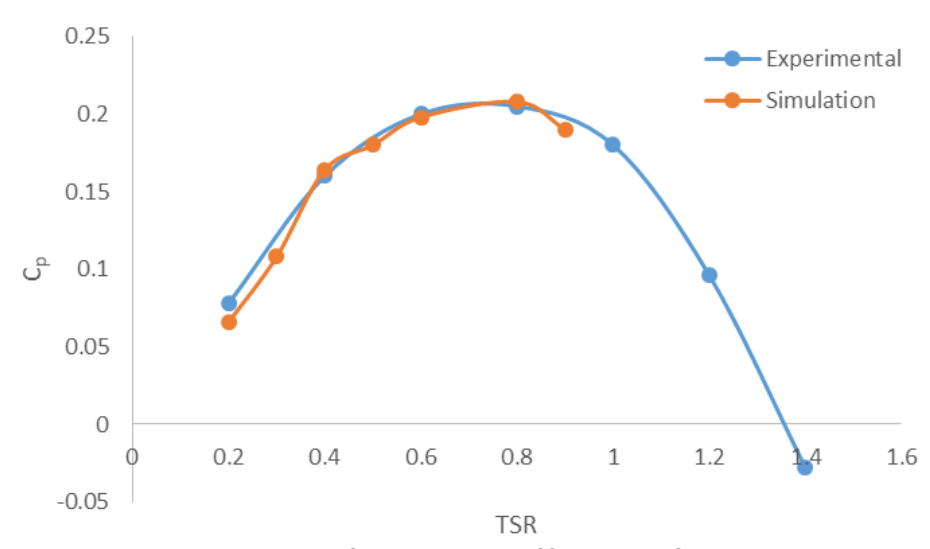

Fig. 9. Comparison of Power Coefficient of Wind Turbines

\section{Results}

\subsection{Wind Turbine Performance in Orthogonal Array Table}

The performance of the wind turbine was achieved by evaluating the power coefficient of the wind turbine. The power coefficient $\left(C_{p}\right)$ is defined as follows,

$C_{P}=C_{M} \cdot \lambda$

where the value of the instantaneous torque coefficient $\left(C_{M}\right)$ of the wind turbine blades can be obtained from a simulation However, in this study, the rotation of the rotor blades was the result of the wake flow induced by a moving car integrated with guiding vanes. Notably, the TSR $(\lambda)$ and rotational speed (RPM) of the wind turbine were not pre-determined compared to other previous research studies on the relationship of moving vehicles and wind turbine applications.

Therefore, the interacting variables such as the rotational speed of the wind turbine and the upstream velocity were studied first. The TSR is defined as follows,

$\lambda=\frac{\omega R}{V}$

where $\omega$ is the rotational speed of the rotor in radians/second, $\mathrm{R}$ is the rotor radius in metres, and $\mathrm{V}$ is the wind speed at the height of the rotor blade hub in metres/second.

The $\mathrm{S} / \mathrm{N}$ ratio is the optimisation criterion and a quality indicator for the Taguchi method. The $\mathrm{S} / \mathrm{N}$ ratio has three different forms, namely, the nominal-the-better, the smaller-the-better, and the larger-the-better. For this study, the larger-the-better form was more suitable for the wind turbine performance. Basically, a larger $\mathrm{S} / \mathrm{N}$ ratio will indicate a larger power coefficient. It is defined as follows,

$\mathrm{S} / \mathrm{N}=-10 \log _{10}\left[\frac{1}{n} \sum_{i=1}^{n} \frac{1}{y_{i}{ }^{2}}\right]$

where for the statistical sample, $y_{i}$, is the power coefficient of the wind turbine, and the number of samples, $n$, is 1 for the simulation study.

Nine simulations, based on the Taguchi Orthogonal Array method, were carried out to evaluate the performance of a wind turbine. In accordance with the level of combinations shown in Table 3, the predicted values of the $C_{P}$ and $S / N$ ratio acquired from the value of the power coefficient were as listed in Table 6. 
Table 6

Calculated Results of $C_{m}, \omega, V, \lambda, C_{P}$ and S/N Ratio

\begin{tabular}{lllllll}
\hline Case & $\begin{array}{l}\text { Eff. Torque } \\
\text { Coefficient, } \\
\mathrm{C}_{\mathrm{m}}\end{array}$ & $\begin{array}{l}\text { Rotational } \\
\text { speed, } \omega \\
(\mathrm{rad} / \mathrm{sec})\end{array}$ & $\begin{array}{l}\text { Effective } \\
\text { velocity, } \mathrm{V} \\
(\mathrm{m} / \mathrm{s})\end{array}$ & $\begin{array}{l}\text { Tip Speed } \\
\text { Ratio, } \lambda\end{array}$ & $\begin{array}{l}\text { Power } \\
\text { Coefficient, } \\
\mathrm{C}_{\mathrm{p}}\end{array}$ & S/N Ratio \\
\hline 1 & 0.0352 & 1.98 & 1.6038 & 0.2247 & 0.00792 & -42.0305 \\
2 & 0.0275 & 1.27 & 1.6064 & 0.1439 & 0.00396 & -48.0447 \\
3 & 0.0648 & 2.45 & 1.9590 & 0.2276 & 0.01476 & -36.6186 \\
4 & 0.0447 & 2.06 & 1.8885 & 0.1985 & 0.00888 & -41.0318 \\
5 & 0.0376 & 1.46 & 1.6972 & 0.1566 & 0.00588 & -44.6077 \\
6 & 0.0207 & 1.21 & 1.4778 & 0.1490 & 0.00309 & -50.2020 \\
7 & 0.0757 & 2.91 & 2.1463 & 0.2468 & 0.01868 & -34.5716 \\
8 & 0.0176 & 1.02 & 1.2356 & 0.1502 & 0.00264 & -51.5518 \\
9 & 0.0195 & 0.92 & 1.1791 & 0.1420 & 0.00277 & -51.1565 \\
\hline
\end{tabular}

From Table 6, it was noticed that the value of the $C_{P}$ was proportional to the $S / N$ ratio (in a negative value). From the table, it could be observed that Simulation Case 7 exhibited the maximum wind turbine performance, where the $C_{P}$ was 0.01868 and the $S / N$ ratio was -34.5716 , whereas the minimum wind turbine performance was for Simulation Case 8 , where the $C_{P}$ was 0.00264 and the $\mathrm{S} / \mathrm{N}$ ratio was -51.5518 .

The $\omega$ can be calculated from data created by the DOF Solver in ANSYS Fluent, as shown in Figure 10(a). The value of the degree of rotation was converted to $\mathrm{rad} / \mathrm{sec}$. The wind velocity data was taken at a reference area (marked with green colour) shown in Figure 5 around the rotating wind turbine domain as the free stream velocity, $\mathrm{V}$, and the result was shown in Figure 10(b) and Figure 10(c) shows that the torque was only generated within a range of time. Later, it was identified that the effective range in terms of the distance travelled by the moving car was from $35 \mathrm{~m}$ (wind turbine location) to $130 \mathrm{~m}$. It was noted that each simulation had a different total simulation time because of the different car speeds, but the same travelled distance. Hence, the moment coefficient and reference velocity were averaged from $35 \mathrm{~m}$ to $130 \mathrm{~m}$ for all the simulations.

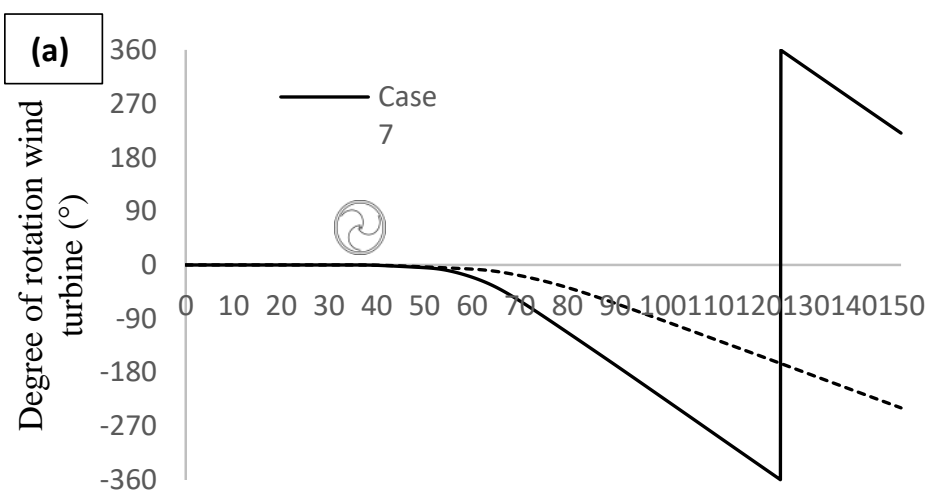

Moving Car Travel Distance (m) 

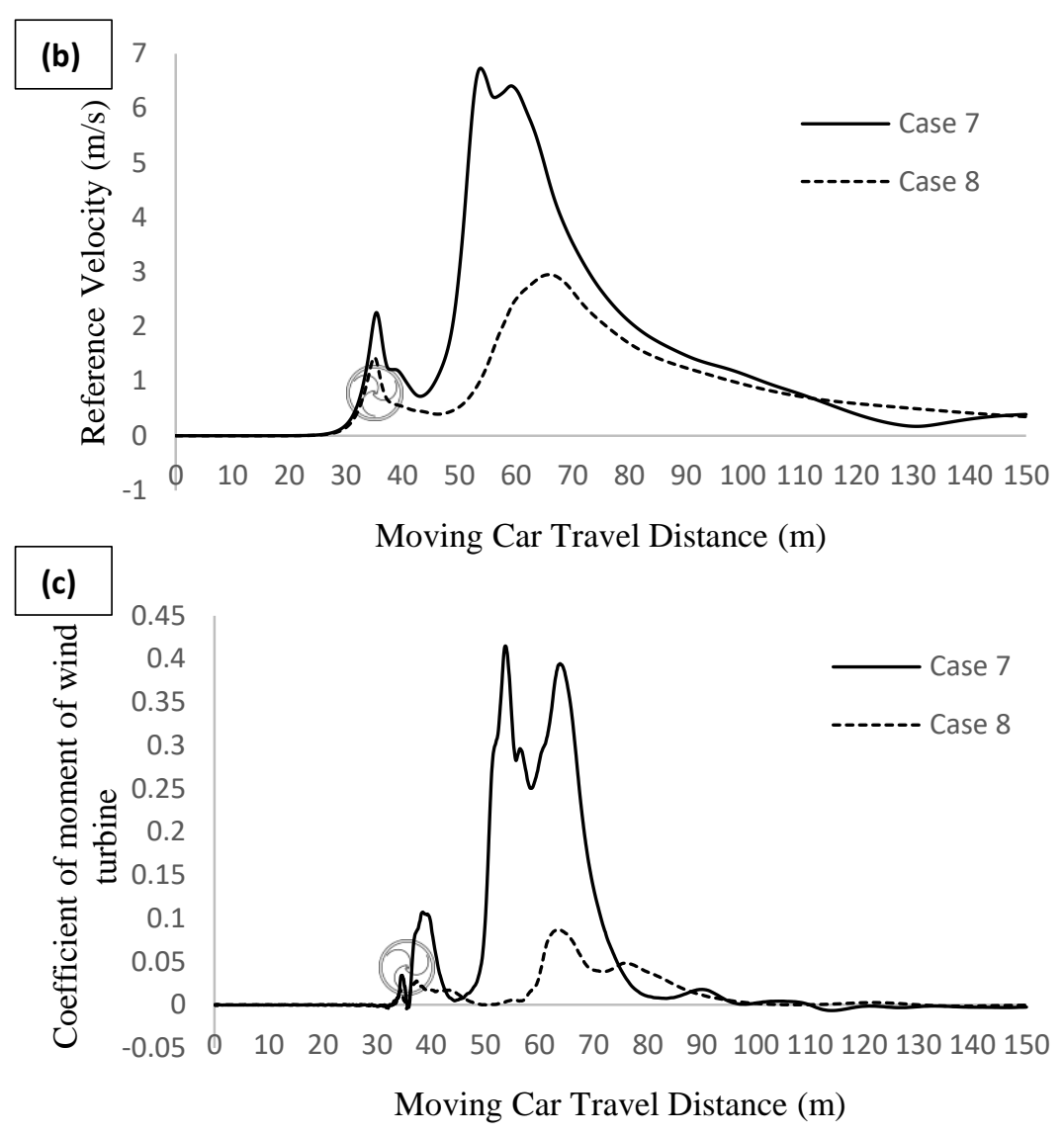

Fig. 10. Data from Simulation Case 7 and Simulation Case 8 for (a) degree of rotation of rotor; (b) reference velocity; (c) moment coefficient of rotor

\subsection{Velocity Contour Distribution}

The wake flow structure of the car is illustrated in Figure 11. As the car moved forward, the rotating vortices started to form in the direction of the moving car. The strong vortex separation was eventually shed and travelled to the outer region. The guide vanes were positioned as shown in Figure 5 to take advantage of the wake separation to direct the wake flow directly to the wind turbine blades.

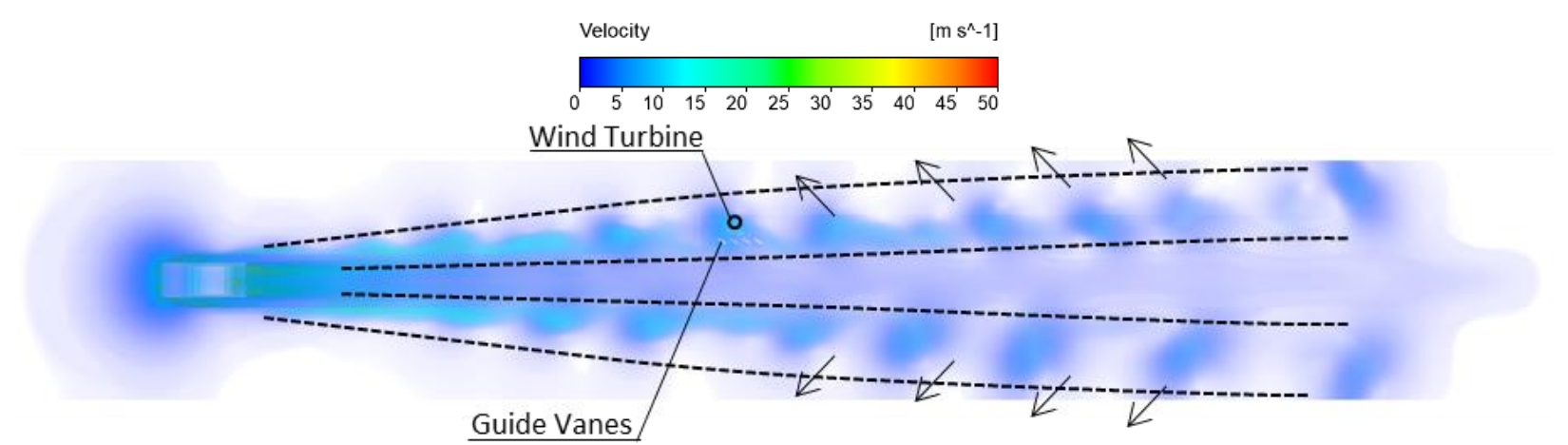

Fig. 11. Wake structure of car moving at $30 \mathrm{~m} / \mathrm{s}$

The operating combinations for Case 7 were $d=0.6 \mathrm{~m}, \alpha=30^{\circ}$ and $V_{C}=30 \mathrm{~m} / \mathrm{s}$, while for Case 8, they were $d=0.6 \mathrm{~m}, \alpha=40^{\circ}$ and $V_{C}=20 \mathrm{~m} / \mathrm{s}$. Figure 12 showed the velocity contours in ZX-plane to 
observed clearly the vortices dispersed from both of the car side until it hits the wind turbine blades. From the same figure, also could be observed that the intensity of the rotating vortices was different in both cases due to the different car speeds. In Case 7, the moving car, which was travelling at a speed of $30 \mathrm{~m} / \mathrm{s}$, showed a high intensity of wake flow compared to Case 8, which showed less intensity, where the moving car was travelling at $20 \mathrm{~m} / \mathrm{s}$. The graph in Figure 10(b) indicated that the maximum velocities for Case 7 and Case 8 were $6.7 \mathrm{~m} / \mathrm{s}$ and $3 \mathrm{~m} / \mathrm{s}$, respectively, which was a difference of almost 50 percent. This showed that a weak wake velocity resulted in a lower power coefficient. Figure 13 shows how the 1-DOF worked. Initially, the wind turbine was at rest, and it only started to rotate when the incoming vortices passed through it.
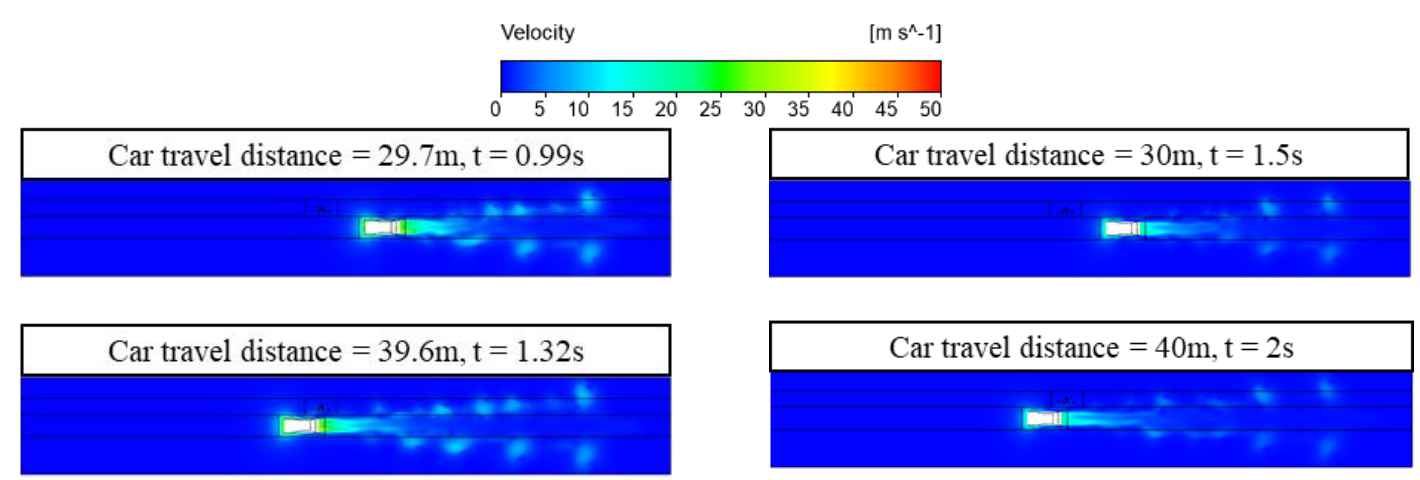

Car travel distance $=54.45 \mathrm{~m}, \mathrm{t}=1.815 \mathrm{~s}$
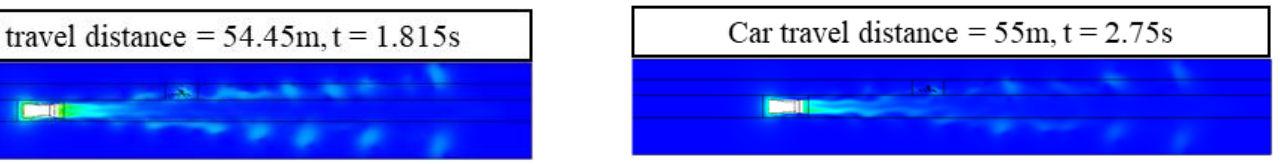

Car travel distance $=64.35 \mathrm{~m}, \mathrm{t}=2.145 \mathrm{~s}$

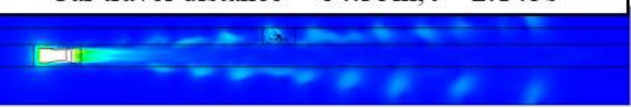

(a)

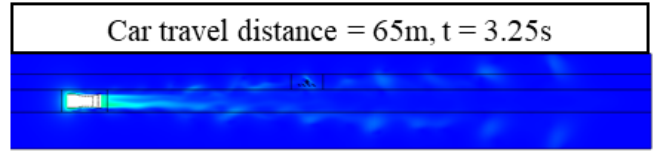

(b)

Fig. 12. Velocity contours ZX-plane at $Y=0.2 \mathrm{~m}$ (a) Case 7, $V_{c}=30 \mathrm{~m} / \mathrm{s}$; (b) Case $8, V_{c}=20$ $\mathrm{m} / \mathrm{s}$
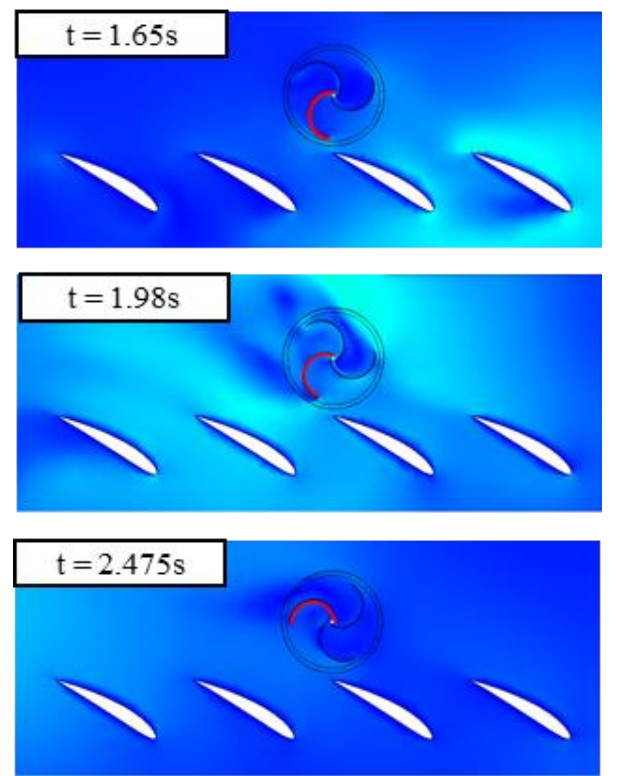

Fig. 13. 1-DOF at wind turbine rotation axis for Case 7 


\subsection{Taguchi Method Analysis}

Based on the $\mathrm{S} / \mathrm{N}$ ratios obtained in Table 6 , the plots of the $\mathrm{S} / \mathrm{N}$ ratio as the mean of three factors are shown in Figure 14. This plot is very important to determine the best level for each factor to find the optimum setting for the wind turbine performance. Basically, this graph was plotted by relating the $\mathrm{S} / \mathrm{N}$ ratios from Table 6 with the matrix in Table 3. For example, the mean $\mathrm{S} / \mathrm{N}$ ratio for Factor $\mathrm{B}$ at Level 1 was calculated by averaging the $S / N$ ratio values for Case 1 , Case 4 and Case 7 because B1 was in those case simulation settings. This step was followed to complete all the plots.

Table 7 shows the results after finding the mean $\mathrm{S} / \mathrm{N}$ ratio for each factor and level. The delta value measured the size of the effect by taking the difference between the highest and lowest characteristic averages for a factor. Next, the assigned rank was to identify which factors had major effects. The largest delta value was given Rank 1, and so on. From Figure 15 it could be concluded that the effects were ranked by car speed $\left(V_{c}\right)>$ angle of guide vanes $(\alpha)>$ distance between guide vanes $(d)$. The delta values for the factors of car speed and angle of the guide vanes were off by only $5 \%$ This figure revealed that the wind turbine performance was not only sensitive to the car speed but also to the angle of the guide vanes, whereas it was insensitive to the distance between the guide vanes compared to the other two factors.

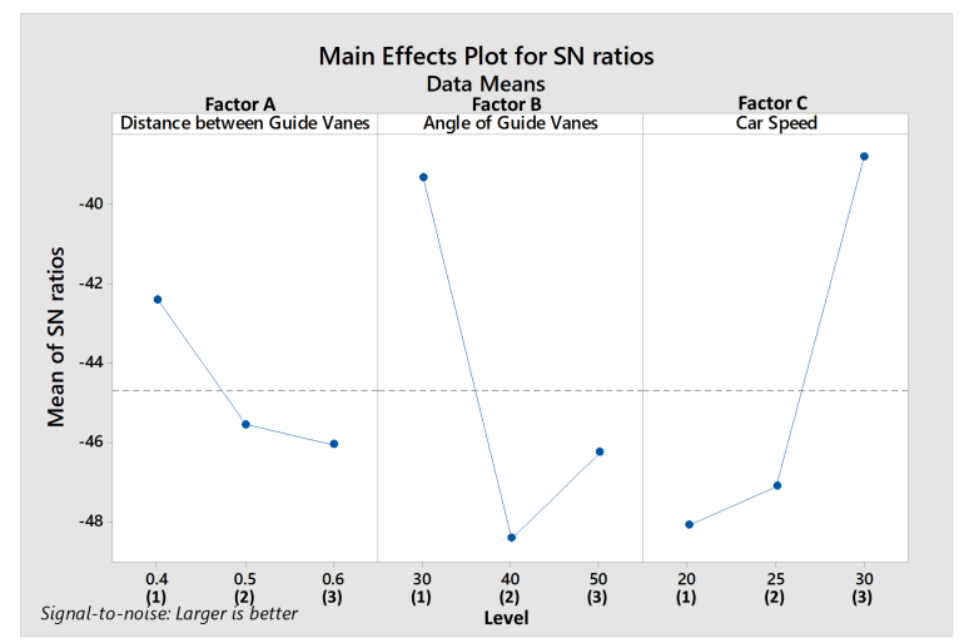

Fig. 14. Mean $\mathrm{S} / \mathrm{N}$ ratio plots

Table 7

Response table for $\mathrm{S} / \mathrm{N}$ ratio (Larger-is-better)

\begin{tabular}{llll}
\hline Level & $\begin{array}{l}\text { Factors } \\
\text { Distance between }\end{array}$ & Angle of GV & Car speed \\
& GV & & \\
\hline 1 & -42.23 & -39.21 & -47.93 \\
2 & -45.28 & -48.07 & -46.74 \\
3 & -45.76 & -45.99 & -38.60 \\
Delta & 3.53 & 8.86 & 9.33 \\
Rank & 3 & 2 & 1 \\
\hline
\end{tabular}




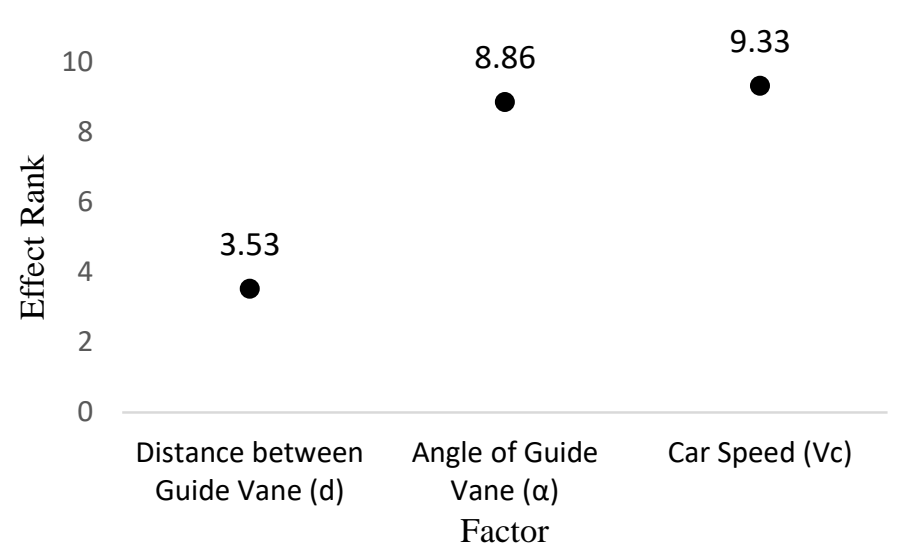

Fig. 15. Factor Effect Rank plots

\subsection{Optimum Setting}

The higher the mean $\mathrm{S} / \mathrm{N}$ ratio, the better the performance of the wind turbine. Hence, the optimum setting for the wind turbine performance can be selected from a combination of the factors with the highest mean $\mathrm{S} / \mathrm{N}$ ratio in each level. With reference to Figure 14 , it was suggested from the perspective of the Taguchi method that the combination of $A 1, B 1$ and $C 3$ was able to maximize the power coefficient of the wind turbine. The optimum setting was $d=0.4 \mathrm{~m}, \alpha=30^{\circ}$, and $V_{c}=30 \mathrm{~m} / \mathrm{s}$. Another simulation was conducted to prove that the optimum setting did indeed produce the maximum power coefficient. Based on the optimum combination, the power coefficient value was 0.0204 , which was $9 \%$ higher than in Case 7.

The optimum combination was compared with a case where guide vanes were not integrated into the wind turbine at $20 \mathrm{~m} / \mathrm{s}, 25 \mathrm{~m} / \mathrm{s}$ and $30 \mathrm{~m} / \mathrm{s}$. Table 8 shows that the higher the car speed, the higher was the power coefficient. Furthermore, with the guide vanes at the optimum setting, the power coefficient could be increased to become $26 \%$ higher than without the installation of the guide vanes at a car speed of $30 \mathrm{~m} / \mathrm{s}$.

Figure 16 shows the distribution of the velocity for the simulation at the optimum setting and without guide vanes at $30 \mathrm{~m} / \mathrm{s}$. The contour time taken was at the highest $\mathrm{Cp}$ reading for each simulation. The guide vanes were able to direct the wake velocity directly to the wind turbine blades, thereby slightly throttling the velocity of the wind as it passed along the aerofoil-shaped guide vanes. Thus, a negative torque was prevented and the power coefficient of the wind turbine was increased.

Table 8

Comparison of $\mathrm{Cp}$ with guide vanes and without guide vanes

\begin{tabular}{llllll}
\hline Case & $\begin{array}{l}\text { Eff. Torque } \\
\text { Coefficient, } \\
\mathrm{C}_{\mathrm{m}}\end{array}$ & $\begin{array}{l}\text { Rotational } \\
\text { speed, } \omega \\
(\mathrm{rad} / \mathrm{sec})\end{array}$ & $\begin{array}{l}\text { Effective } \\
\text { velocity, V } \\
(\mathrm{m} / \mathrm{s})\end{array}$ & $\begin{array}{l}\text { Tip Speed } \\
\text { Ratio, } \lambda\end{array}$ & $\begin{array}{l}\text { Power } \\
\text { Coefficient, } \\
\mathrm{C}_{\mathrm{p}}\end{array}$ \\
\hline Without GV @ 20m/s & 0.0127 & 0.76 & 0.9474 & 0.1460 & 0.00185 \\
Without GV @ 25m/s & 0.0388 & 1.83 & 1.9272 & 0.1728 & 0.00671 \\
Without GV @ 30m/s & 0.0732 & 2.81 & 2.3154 & 0.2209 & 0.01616 \\
Optimum Setting & 0.0875 & 3.28 & 2.5608 & 0.2331 & 0.0204 \\
\hline
\end{tabular}




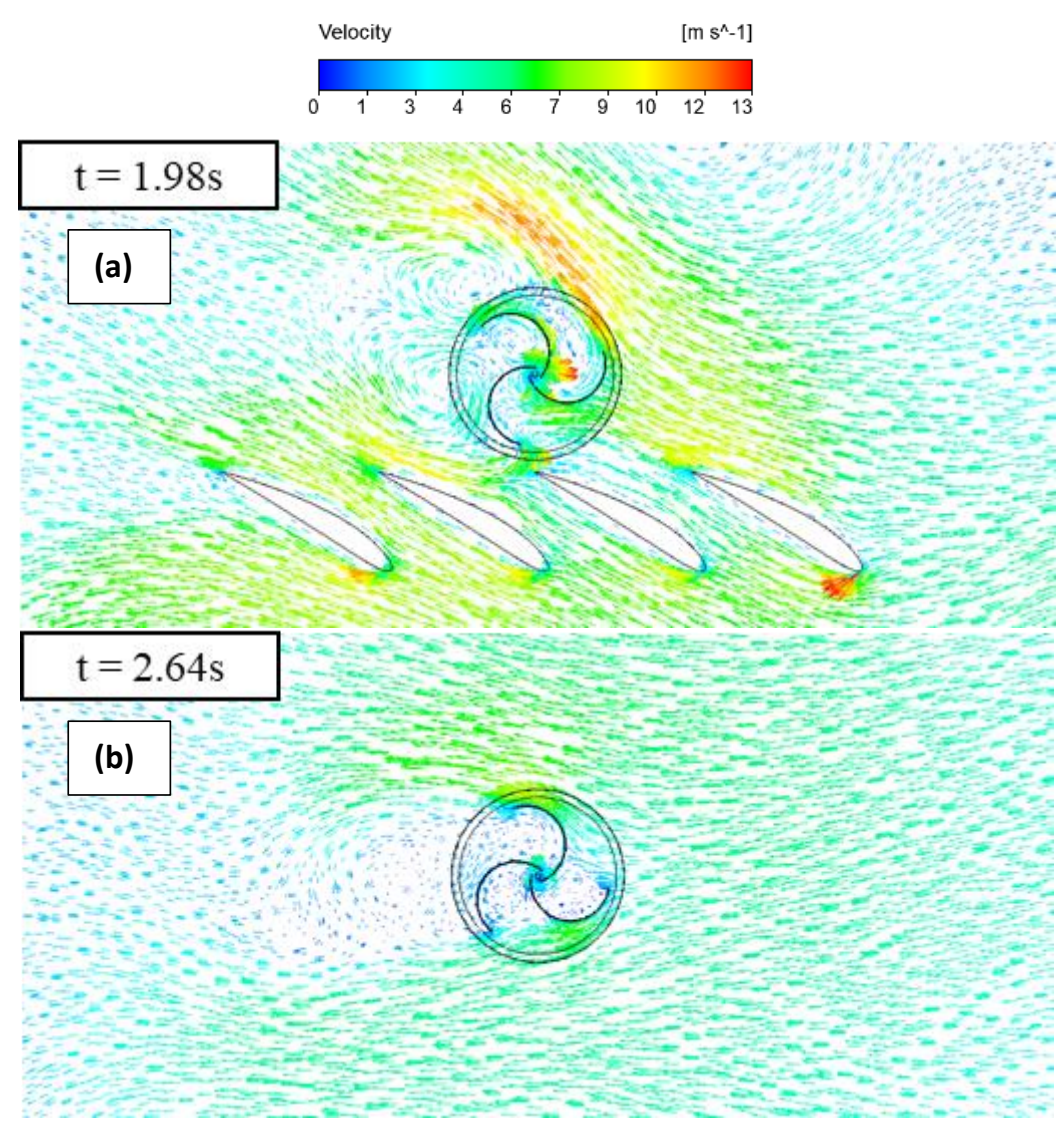

Fig. 16. Velocity distribution for case of (a) optimum setting (b) without GV @ 30 m/s

\section{Conclusions}

Simulations were conducted to study the interaction between a moving car and a wind turbine integrated with guide vanes to determine the power coefficient. The effects of the three factors of distance between the guide vanes $(d)$, angle of the guide vanes $(\alpha)$, and car speed $\left(V_{c}\right)$, along with three levels each were analysed using the Taguchi method. An orthogonal array of L9 (9 simulation cases) was carried out. It was found that the power coefficient was influenced by these factors in the order of strength of $V_{C}>\alpha>d$. The factors $V_{C}$ and $\alpha$ had a greater effect than the factor $d$ in determining the $\mathrm{Cp}$. The higher the car speed, the higher was the wake velocity produced. However, if the angle of the guide vanes was increased, they might have blocked the wind, thus, reducing the performance of the wind turbine. The $\mathrm{S} / \mathrm{N}$ ratio analysis also suggested that the optimum setting of $d=0.4 \mathrm{~m}, \alpha=30^{\circ}$, and $V_{C}=30 \mathrm{~m} / \mathrm{s}$ would have maximized the $\mathrm{Cp}$ and effectively harvested the wake velocity from the moving car. The observation of the velocity contours also showed that the aerofoilshaped guide vanes managed to throttle and direct the wake flow passing through them. A comparative study of the power coefficient of the wind turbines with and without the installation of guide vanes at the same car speed of $30 \mathrm{~m} / \mathrm{s}$ showed that the optimum setting was able to increase the $\mathrm{Cp}$ to $26 \%$. The results that were obtained provided better insights into the interaction between wind turbines and moving cars in harvesting the wake velocity of the wind power source.

\section{Acknowledgements}

This research was funded by a grant from the Ministry of Higher Education of Malaysia (FRGS Grant R.J130000.7824.4X172). 


\section{References}

[1] Zaharim, Azami, Siti Khadijah Najid, Ahmad Mahir Razali, and Kamaruzzaman Sopian. "Wind speed analysis in the east coast of Malaysia." European Journal of Scientific Research 32, no. 2 (2009): 208-215.

[2] Saqr, Khalid M., and Md Nor Musa. "RANS simulation of the turbulent flow field in the vicinity of the Ahmed reference car model." New Aspects of Fluid Mechanics, Heat Transfer and Environment. Wseas, Taipi (2010): 2126.

[3] Hegde, Shreyas S., Anand Thamban, Shah Palash Manish Bhai, Arham Ahmed, Meet Upadhyay, Ashish Joishy, and Arun Mahalingam. "Highway mounted horizontal axial flow turbines for wind energy harvesting from cruising vehicles." In ASME 2016 International Mechanical Engineering Congress and Exposition. American Society of Mechanical Engineers Digital Collection, 2016. https://doi.org/10.1115/IMECE2016-65194

[4] Al-Aqel, A. A., B. K. Lim, EE Mohd Noor, Tze Chuen Yap, and S. A. Alkaff. "Potentiality of small wind turbines along highway in Malaysia." In 2016 International Conference on Robotics, Automation and Sciences (ICORAS), pp. 1-6. IEEE, 2016. https://doi.org/10.1109/ICORAS.2016.7872634

[5] Santhakumar, Senthilvel, Ilamathi Palanivel, and Krishnanand Venkatasubramanian. "An experimental study on the rotational behaviour of a Savonius wind turbine for two-lane highway applications." Journal of the Brazilian Society of Mechanical Sciences and Engineering 40, no. 4 (2018): 1-12. https://doi.org/10.1007/s40430-018-1158-9

[6] Altan, Burçin Deda, Mehmet Atılgan, and Aydoğan Özdamar. "An experimental study on improvement of a Savonius rotor performance with curtaining." Experimental Thermal and Fluid Science 32, no. 8 (2008): 1673-1678. https://doi.org/10.1016/i.expthermflusci.2008.06.006

[7] Promdee, Chatchai, and Chonlatee Photong. "Effects of wind angles and wind speeds on voltage generation of savonius wind turbine with double wind tunnels." Procedia Computer Science 86 (2016): 401-404. https://doi.org/10.1016/j.procs.2016.05.044

[8] Irabu, Kunio, and Jitendro Nath Roy. "Characteristics of wind power on Savonius rotor using a guide-box tunnel." Experimental Thermal and Fluid Science 32, no. 2 (2007): 580-586. https://doi.org/10.1016/j.expthermflusci.2007.06.008

[9] Son, Sung-Woo, Patrick Mark Singh, and Young-Do Choi. "Influence of guide vane shape on the performance and internal flow of a cross flow wind turbine." Journal of the Korean Society of Marine Engineering 37, no. 2 (2013): 163-169. https://doi.org/10.5916/jkosme.2013.37.2.163

[10] Korprasertsak, Natapol, and Thananchai Leephakpreeda. "CFD-based power analysis on low speed vertical axis wind turbines with wind boosters." Energy Procedia 79 (2015): 963-968. https://doi.org/10.1016/i.egypro.2015.11.594

[11] Wang, Qiankun, Weijie Fang, Renaud de Richter, Chong Peng, and Tingzhen Ming. "Effect of moving vehicles on pollutant dispersion in street canyon by using dynamic mesh updating method." Journal of Wind Engineering and Industrial Aerodynamics 187 (2019): 15-25. https://doi.org/10.1016/i.jweia.2019.01.014

[12] Fujisawa, Nobuyuki. "On the torque mechanism of Savonius rotors." Journal of Wind Engineering and Industrial Aerodynamics 40, no. 3 (1992): 277-292. https://doi.org/10.1016/0167-6105(92)90380-S

[13] Wenehenubun, Frederikus, Andy Saputra, and Hadi Sutanto. "An experimental study on the performance of Savonius wind turbines related with the number of blades." Energy Procedia 68 (2015): $297-304$. https://doi.org/10.1016/i.egypro.2015.03.259

[14] Ricci, Renato, Roberto Romagnoli, Sergio Montelpare, and Daniele Vitali. "Experimental study on a Savonius wind rotor for street lighting systems." Applied Energy $161 \quad$ (2016): $143-152$. https://doi.org/10.1016/i.apenergy.2015.10.012

[15] Airfoil Tools. "NACA 4412 (naca4412-il)." Airfoil Tools, November 18, 2020.

[16] Deisadze, Lucas, Drew Digeser, Christopher Dunn, and Dillon Shoikat. "Vertical Axis Wind Turbine Evaluation and Design." Worcester Polytechnic Institute (2013).

[17] Nasef, M. H., W. A. El-Askary, A. A. Abdel-Hamid, and H. E. Gad. "Evaluation of Savonius rotor performance: Static and dynamic studies." Journal of Wind Engineering and Industrial Aerodynamics 123 (2013): 1-11. https://doi.org/10.1016/j.jweia.2013.09.009

[18] Akwa, João Vicente, Gilmar Alves da Silva Júnior, and Adriane Prisco Petry. "Discussion on the verification of the overlap ratio influence on performance coefficients of a Savonius wind rotor using computational fluid dynamics." Renewable Energy 38, no. 1 (2012): 141-149. https://doi.org/10.1016/i.renene.2011.07.013

[19] Tian, Wenlong, Zhaoyong Mao, Xinyu An, Baoshou Zhang, and Haibing Wen. "Numerical study of energy recovery from the wakes of moving vehicles on highways by using a vertical axis wind turbine." Energy 141 (2017): 715-728. https://doi.org/10.1016/i.energy.2017.07.172 
[20] Selvaraju, P. N., K. M. Parammasivam, and Dr G. Devaradjane Shankar. "Analysis of Drag and Lift performance in sedan car model using CFD." Journal of Chemical and Pharmaceutical Sciences www.jchps.com ISSN 974 (2015): 2115.

[21] Lye, Gerard. "DRIVEN: 2016 Proton Saga first impressions review - meet the true challenger to the Perodua Bezza." PAULTAN.ORG, September 24, 2016.

[22] Rumsey, Christopher. "2DN44: 2D NACA 4412 Airfoil Trailing Edge Separation." Langley Research Center Turbulence Modeling Resource. Accessed November 18, 2020.

[23] Torresi, Marco, Fabio A. De Benedittis, Bernardo Fortunato, and Sergio M. Camporeale. "Performance and flow field evaluation of a Savonius rotor tested in a wind tunnel." Energy Procedia 45 (2014): 207-216. https://doi.org/10.1016/i.egypro.2014.01.023 